\title{
Determination of Meclofenoxate Content in Meclofenoxate Hydrochloride for Injection by DSC and ${ }^{1} \mathrm{H}-\mathrm{NMR}$
}

\author{
Peipei Zhang1, Tingting Liư ${ }^{2}$ Xuejiao Xu², Shuyu Liu ${ }^{*}$, Dongying Chen ${ }^{2 *}$ \\ ${ }^{1}$ School of Chemistry and Chemical Engineering, Shanghai University of Engineering Science, Shanghai, China \\ ${ }^{2}$ Laboratory of Pharmaceutical Analysis, Shanghai Institute of Materia Medica, Chinese Academy of Sciences, \\ Shanghai, China \\ Email: *liushuyu@sues.edu.cn, "dychen@mail.shcnc.ac.cn
}

Received 10 December 2015; accepted 22 January 2016; published 25 January 2016

Copyright (C) 2016 by authors and Scientific Research Publishing Inc.

This work is licensed under the Creative Commons Attribution International License (CC BY).

http://creativecommons.org/licenses/by/4.0/

c) (i) Open Access

\begin{abstract}
Two simple and rapid analytical methods (DSC and ${ }^{1} \mathrm{H}-\mathrm{NMR}$ ), are proposed for determination of meclofenoxate in meclofenoxate hydrochloride for injection. DSC thermogram is recorded without any sample pretreatment. The response linearity is ensured by linear determination factors $\mathbf{R}^{2}$, which is $\mathbf{0 . 9 9 8 2}$. The recoveries of meclofenoxate hydrochloride in sterile powder for injection are from $98.3 \%$ to $102.3 \%(n=3)$. The quantitative ${ }^{1} \mathrm{H}$-NMR is quick and simple to use. The quantitation of meclofenoxate is reproducible and the relative standard deviation is $1.0 \%$. The accuracy of two methods is validated by comparison with the results obtained by HPLC. The results show that the two methods are capable of quantifying the content of meclofenoxate in meclofenoxate hydrochloride for injection.
\end{abstract}

\section{Keywords}

Meclofenoxate Hydrochloride, DSC, ${ }^{1}$ H-NMR, Analysis

\section{Introduction}

Meclofenoxate [CAS number 51-68-3] is one of the older nootropic drugs used to treat the symptoms of senile dementia and Alzheimer's disease (Figure 1) [1]. It is a white powder, soluble in cold water and methanol, sparingly soluble in cold isopropanol and acetone and practically insoluble in benzene, ether and chloroform.

${ }^{*}$ Corresponding authors.

How to cite this paper: Zhang, P.P., Liu, T.T., Xu, X.J., Liu, S.Y. and Chen, D.Y. (2016) Determination of Meclofenoxate Content in Meclofenoxate Hydrochloride for Injection by DSC and ${ }^{1} \mathrm{H}-\mathrm{NMR}$. American Journal of Analytical Chemistry, 7, 92-98. http://dx.doi.org/10.4236/ajac.2016.71009 


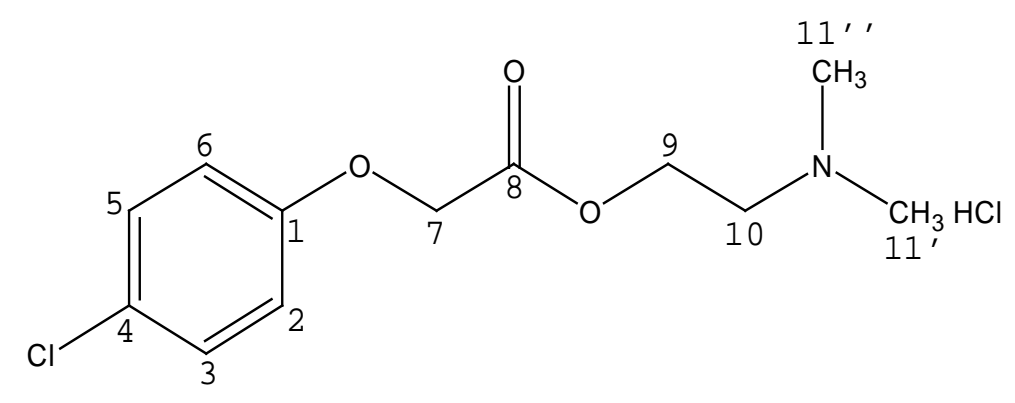

Figure 1. Chemical structure of meclofenoxate hydrochloride.

However, meclofenoxate containing ester is easy to produce hydrolysis reaction, resulting in that its medicinal property becomes poor. Several different methods have been used for the determination of meclofenoxate including electrochemical method [1]-[3], proton magnetic resonance spectroscopy, capillary electrophoresis [4], resonance Rayleigh scattering method [5], and high performance liquid chromatography [6]-[8].

The meclofenoxate hydrochloride in sterile powder for injection contains meclofenoxate hydrochloride and mannitol (see in Figure 1). The content of meclofenoxate hydrochloride in sterile powder for injection is determined by HPLC in China Pharmacopeia [2]. Although this method is comparatively accurate, it is restained by many conditions. For instance, the meclofenoxate hydrochloride samples should be analysed as soon as possible after the preparation stage. The analysis time of each sample is long. In addition, the meclofenoxate hydrochloride is prepared in buffer solution of $\mathrm{pH}=2.5$ to prevent hydrolysis. This paper attempted to use some instrumental methods such as differential scanning calorimetry (DSC) and nuclear magnetic resonance (NMR) in the detection of principal component content of the meclofenoxate hydrochloride for injection. The DSC and NMR methods are rapid, convenient, accurate, and highly specific, and do not require an absorption coefficient. DSC thermogram is recorded without any sample pretreatment. The quantitative NMR method, which does not require consideration of impurities or a reference standard of known content, but only uses a common chemical substance of known content for comparison, can determine the absolute contents of a drug. We acquire the spectra of meclofenoxate hydrochloride for injection during the determination process and to investigate whether the content of the meclofenoxate hydrochloride for injection can be determined via the methods (DSC and NMR) and how the results correlate with the established method (HPLC). The results show that the two methods are capable of quantifying the content of meclofenoxate in meclofenaxate hydrochloride for injection. The purpose of this work was to establish two simple and rapid analytical methods (DSC and ${ }^{1} \mathrm{H}-\mathrm{NMR}$ ) for determination of meclofenoxate in meclofenaxate hydrochloride for injection.

\section{Experimental}

\subsection{Apparatus and Reagents}

Dionex Ultimate 3000 liquid chromatograph (Dionex, USA); Linseis DSC-PT10 differential scanning calorimetry instrument (Germany); Sartorius pB-10 pH meter; Brucker AVANCE II 400 NMR spectrometer (Bruker, USA); Mettler Toledo AB135-S electronic balance (Mettler, German); Shimadzu AUY120 electronic balance; Millipore pure water instrument.

Octane sulfonate (batch no. 30204861), mannitol (batch no. 980708) and phosphoric acid (batch no. 10015418) were purchased from the Sinopharm Chemical Reagent Co., Ltd. (Shanghai, China). The maleic acid (purity 99.0\%) was purchased from Sigma, USA. D2O (D, 99.9\%) was from Cambridge Isotope Laboratories Inc., UK. Acetonitrile was HPLC grade from Merck, German. High-purity water was obtained from a Milli-Q system (Millipore, Bedford, MA, USA, Milli-Q filtered, $18.2 \mathrm{M} \Omega / \mathrm{cm}$ ). The meclofenoxate hydrochloride bulk drug was from Shanghai Wandai Pharmacaceutical Co., Ltd. The meclofenoxate hydrochloride in sterile powder for injection was from Hunan Wuzhoutong Pharmaceutical Co., Ltd. (Hunan, China).

\subsection{HPLC Determination}

The experiment was performed using an online degasser, an autosampler and a Phenomenex luna C18 Column ( $5 \mu \mathrm{m}, 250 \mathrm{~mm} \times 4.6 \mathrm{~mm}$ i.d.). The chromatographic elution was accomplished isocratically with Octanesulfo- 
nate solution $(0.05 \mathrm{~mol} / \mathrm{l}, \mathrm{pH} 2.5)-\mathrm{ACN}(65: 35 \mathrm{v} / \mathrm{v})$ at a flow rate of $1 \mathrm{ml} / \mathrm{min}$. The temperature was maintained at $30^{\circ} \mathrm{C}$ and the injection volume was $20 \mu \mathrm{L}$. DAD detection was achieved in the range of $200-800 \mathrm{~nm}, 225 \mathrm{~nm}$ results were used for quantitative purposes.

Octanesulfonate solution ( $0.05 \mathrm{~mol} / \mathrm{l}, \mathrm{pH} 2.5)$ : Weigh $10.81 \mathrm{~g}$ of Octanesulfonate, transfer into a beaker, add an appropriate amount of water to dissolve, adjust to $\mathrm{pH} 2.5$ with phosphoric acid solution and add water to make $1000 \mathrm{ml}$. The prepared solution was filtered with $0.22 \mu \mathrm{m}$ membrane.

Mixed solvent (ACN: $\left.\mathrm{H}_{2} \mathrm{O}=6: 4\right)$ : $\mathrm{Mix} 200 \mathrm{ml}$ of water adjusted to $\mathrm{pH} 2.5$ with phosphoric acid solution with $300 \mathrm{ml}$ of acetonitrile.

Weigh $25 \mathrm{mg}$ of meclofenoxate hydrochloride bulk drug, transfer into a $25 \mathrm{ml}$ volumetric flask, add acetonitrile to a constant volume is $25 \mathrm{ml}$ and filter with $0.45 \mu \mathrm{m}$ organic membrane to make $1 \mathrm{mg} / \mathrm{ml}$ meclofenoxate hydrochloride solution. Take appropriate amounts of the solution in $10 \mathrm{ml}$ volumetric flasks to make $0.5,0.25$, $0.125,0.0625,0.0312 \mathrm{mg} / \mathrm{ml}$ meclofenoxate hydrochloride standard solution.

Weigh $25 \mathrm{mg}$ of meclofenoxate hydrochloride in sterile powder for injection, transfer into a $25 \mathrm{ml}$ volumetric flask, add mixed solvent to a constant volume is $25 \mathrm{ml}$ and filter with $0.45 \mu \mathrm{m}$ organic membrane.

\subsection{DSC Determination}

Nitrogen (99.999\% purity) was the purge gas flowing at $10 \mathrm{ml} / \mathrm{min}$. Samples of 1 - $3 \mathrm{mg}$ were weighed into aluminum pans and covers were hermetically sealed into place. An empty, hermetically sealed aluminum pan was used as reference. Samples were preheated at $50^{\circ} \mathrm{C}$ and were heated to $250^{\circ} \mathrm{C}$ at a rate of $10^{\circ} \mathrm{C} / \mathrm{min}$.

\section{4. ${ }^{1} \mathrm{H}-\mathrm{NMR}$ Determination}

Sample solutions were $29.60 \mathrm{mg} / \mathrm{ml}$ and the internal standard solution of maleic acid was $2.63 \mathrm{mg} / \mathrm{ml}$; the solvent was $\mathrm{D}_{2} \mathrm{O}$. The experiments were carried out with the following parameters optimized for qNMR: $90^{\circ}$ pulse of 11.10 usec, delay of $20 \mathrm{~s}, 16$ scans and gain of 10 . Phase and baseline corrections were done manually.

\section{Results and Discussion}

\subsection{HPLC Determination}

Six concentrations ranging from $0.0312 \mathrm{mg} / \mathrm{ml}$ to $1.0 \mathrm{mg} / \mathrm{ml}$ were used to obtain the calibration curve. A straight line with an excellent correlation coefficient with negligible deviations from linearity at low and high concentrations was obtained. The linear equation was $\mathrm{Y}=712.13 \mathrm{X}-1.5178\left(\mathrm{R}^{2}=1\right)$. $\mathrm{X}$ is concentration and $\mathrm{Y}$ is peak area. The UV chromatogram of meclofenoxate hydrochloride in sterile powder for injection is shown in Figure 2. The content of meclofenoxate hydrochloride in sterile powder for injection is $38.8 \%$ calculated by the linear equation.

\subsection{DSC Determination}

The meclofenoxate hydrochloride bulk drug was determined in the different weight to get the relationship between the melting energy and the weitht of meclofenoxate hydrochloride. Figure 3 gave the calibration curves as the normalized area of the melting peaks (Energy) and plotted against the weight of meclofenoxate hydrochloride. The energy of meclofenoxate hydrochloride is proportional to its weight (range from 1.0 to $3 \mathrm{mg}$ ). The linear equation was $\mathrm{y}=136.31 \mathrm{x}+5.6819$. The $\mathrm{y}$ is energy and the $\mathrm{x}$ is weigh. The correlation coefficient of the best-fit line was 0.9982 , indicating a linear correlation between the energy and the weight of meclofenoxate hydrochloride. Based on this single set of data, DSC appeared to be a suitable technique for the detection of meclofenoxate hydrochloride.

The mixtures of meclofenoxate hydrochloride and mannitol were made over the range of $35 \%$ to $52 \% \mathrm{w} / \mathrm{w}$ meclofenoxate hydrochloride respectively. The content of meclofenoxate hydrochloride was determined by DSC method. Table 1 gave a comparison between the theoretical meclofenoxate hydrochloride content and determined meclofenoxate hydrochloride content in mixtures by DSC method. The recoveries of meclofenox-ate hydrochloride in sterile powder for injection were from $98.3 \%$ to $102.3 \%(n=3)$.

Figure 4 gave DSC curves of the meclofenoxate hydrochloride in sterile powder for injection. The content of meclofenoxate hydrochloride in sterile powder for injection was $39.3 \%$ by the linear equation of quantitative DSC method. 


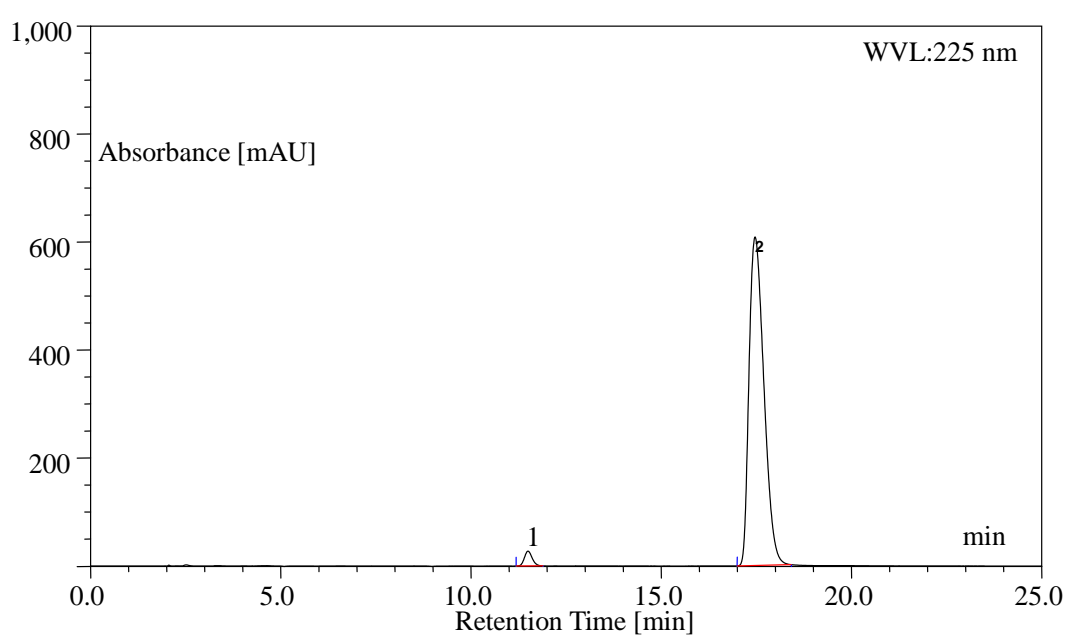

Figure 2. Temperature dependence of the concentration of water saturated in pure nitrobenzene. 1, hydrolyzate, Rt $=11.50 \mathrm{~min}$, Area $=6.4806 \mathrm{mAU} * \mathrm{~min} ; 2$, meclofenoxate hydrochloride, $\mathrm{Rt}=17.47 \mathrm{~min}$, Area $=274.7627 \mathrm{mAU} * \mathrm{~min}$.

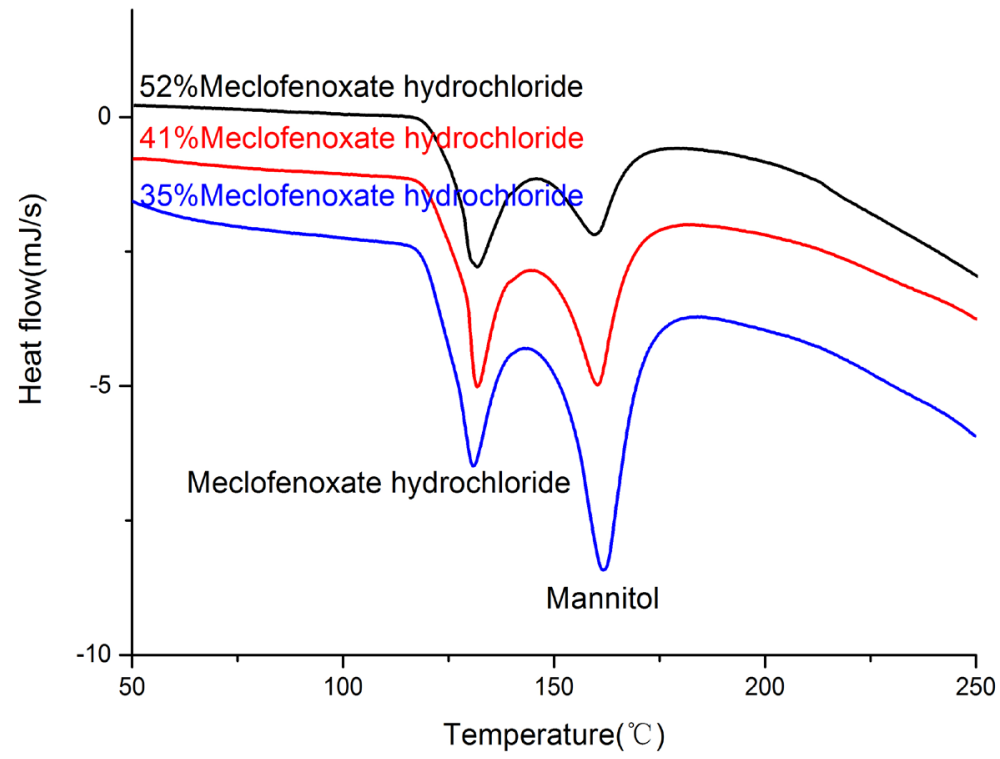

Figure 3. A overlay of the DSC curves of three blends of meclofenoxate hydrochloride and mannitol.

Table 1. The content of meclofenoxate hydrochloride in the mixtures of meclofenoxate hydrochloride and mannitol.

\begin{tabular}{cccc}
\hline No. & Theoretical Content/\% & Determined Content/\% & Recovery/\% \\
\hline 1 & 52.4 & 52.8 & 100.7 \\
2 & 41.2 & 40.5 & 98.3 \\
3 & 35.0 & 35.8 & 102.3 \\
\hline
\end{tabular}

\section{3. ${ }^{1} \mathrm{H}-\mathrm{NMR}$ Determination}

For quantitative methods, the internal standard method is used widely at present. The purity of the analyte can be calculated as follows [9]: 


$$
P_{x}=\frac{I_{x}}{I_{S t d}} \times \frac{N_{S t d}}{N_{x}} \times \frac{M_{x}}{M_{S t d}} \times \frac{m_{S t d}}{m} \times P_{S t d}
$$

where $M_{x}$ and $M_{S t d}$ are the molar masses of the analyte and the standard, respectively, $m$ is the weighed mass of the investigated sample, $m_{S t d}$ and $P_{S t d}$ are the weighed mass and the purity of the standard, and $N_{S t d}$ and $I_{S t d}$ correspond to the number of spins and the integrated signal area of a (typical) NMR line of the standard.

The most important conditions for an internal standard are its solubility and its chemical interaction with the analyte. Maleic acid is easily solved in $\mathrm{D}_{2} \mathrm{O}$ and the chemical shift is 6.319 which best separated with meclofenoxate showed in Figure 5. Furthermore, there is no chemical interaction between them. Therefore, maleic acid is selected as the internal standard.

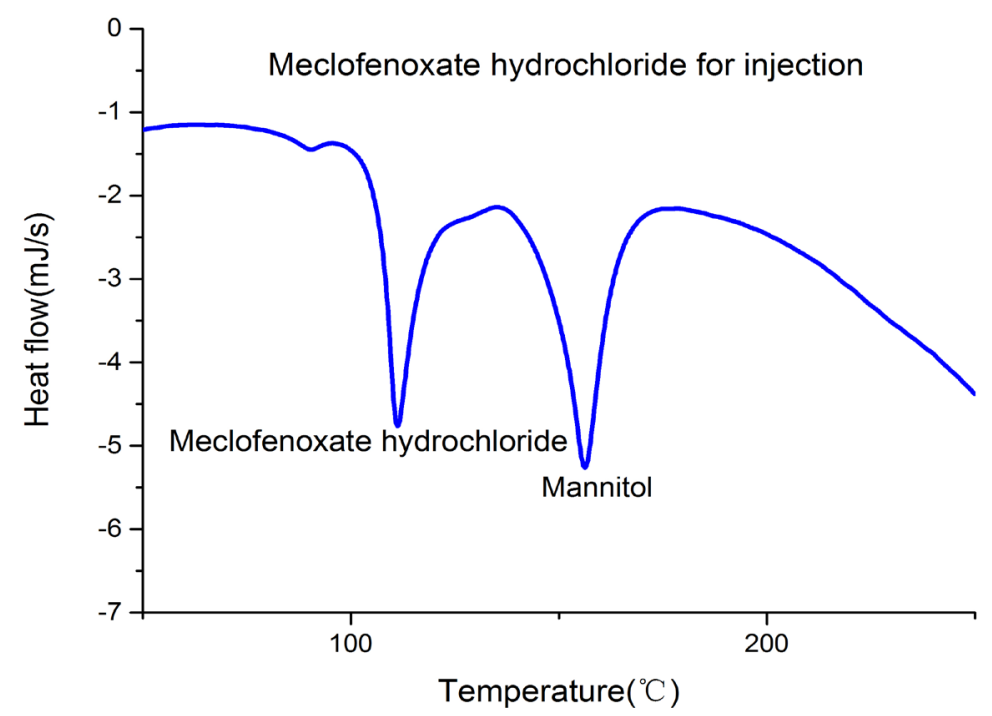

Figure 4. DSC-thermogram of meclofenoxate hydrochloride in sterile powder for injection. meclofenoxate hydrochloride, melting point $=111.4^{\circ} \mathrm{C}$; mannitol, melting point $=156.3^{\circ} \mathrm{C}$.

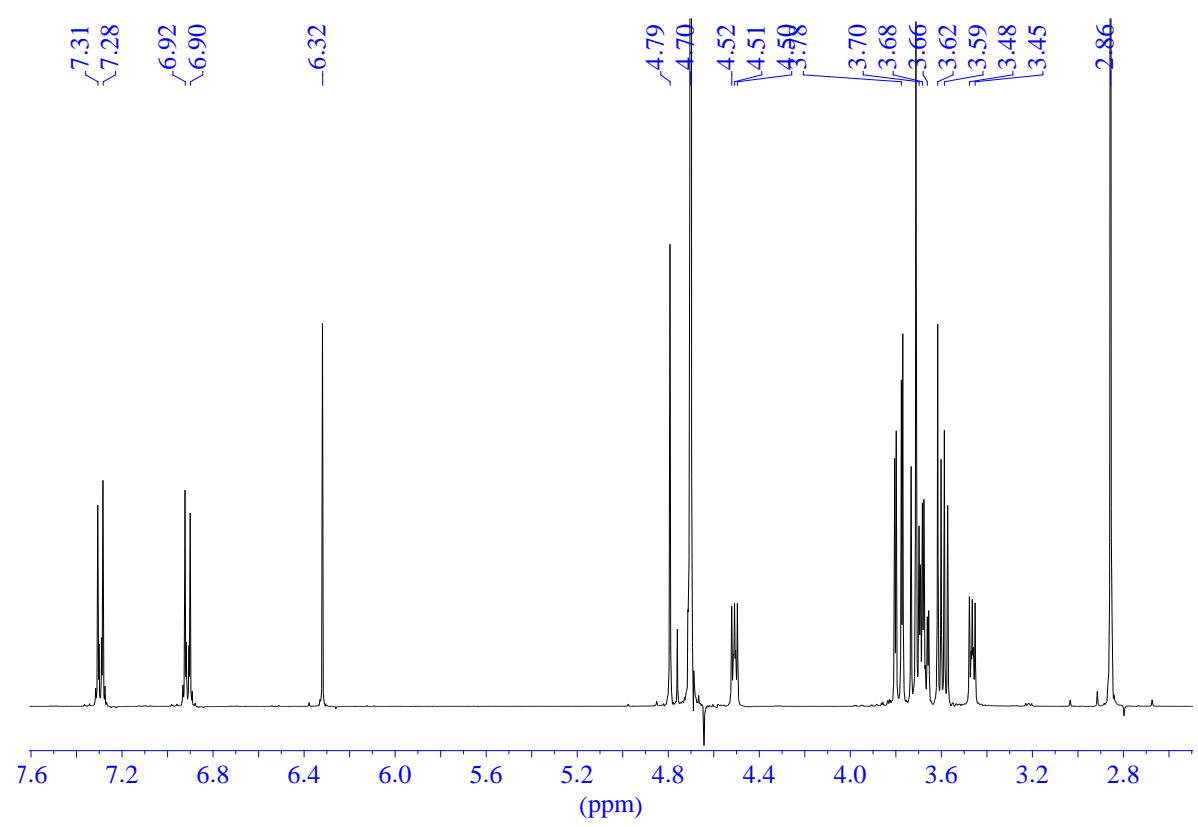

Figure 5. ${ }^{1} \mathrm{H}$ NMR spectrum of meclofenoxate hydrochloride, with internal standard $(\delta=$ 6.319 , singlet $)$ and $\mathrm{D}_{2} \mathrm{O}(\delta=4.702)$ peaks. 
The ${ }^{1} \mathrm{H}$ NMR data of meclofenoxate hydrochloride in sterile powder for injection is shown in Table 2. The monitor signal is chosen as the one that is best separated from the other signals for meclofenoxate in the experiment. Five monitor signals of meclofenoxate are selected for quantization (Table 3). As shown in Table 3, the content of meclofenoxate hydrochloride in sterile powder for injection was $39.1 \%$ by the internal standard method of quantitative NMR. The quantitation of meclofenaxate was reproducible and the relative standard deviation is $1.0 \%$.

We compare the different method for the determination of meclofenoxate hydrochloride for injection in Table 4. According to the result of HPLC, the content of meclofenoxate hydrochloride determinated by the other two methods (DSC and NMR) was accurate.

\section{Conclusion}

The determination of active content of compounds in pharmaceutical preparations of meclofenoxate is often achieved by HPLC. In this paper, we reported two simple, precise, and accurate methods for the determination of meclofenoxate content in meclofenoxate hydrochloride for injection. There is no sample pretreatment and sample hydrolyzation in the DSC determination. The advantages of quantitative NMR include simple sample

Table 2. ${ }^{1} \mathrm{H}$ NMR data of meclofenoxate hydrochloride in sterile powder for injection $\left(\mathrm{D}_{2} \mathrm{O}\right)$.

\begin{tabular}{ccccc}
\hline & No. & $\delta_{\mathrm{H}}(\mathrm{ppm})$ & Peak & $\mathrm{J}(\mathrm{Hz})$ \\
\hline Meclofenoxate hydrochloride & $3-\mathrm{CH}, 5-\mathrm{CH}$ & 7.295 & $\mathrm{~d}$ & 8.8 \\
& $2-\mathrm{CH}, 6-\mathrm{CH}$ & 6.912 & $\mathrm{~d}$ & 9.2 \\
Mannitol & $7-\mathrm{CH}_{2}$ & 4.793 & $\mathrm{~s}$ & \\
& $9-\mathrm{CH}_{2}$ & 4.509 & $\mathrm{t}$ & $4.8,5.2,10.0$ \\
Meclofenoxate hydrochloride & & $3.593-3.802$ & $\mathrm{~m}$ & \\
& $10-\mathrm{CH}_{2}$ & 3.465 & $\mathrm{~m}$ & \\
\hline
\end{tabular}

Table 3. Assay of major constituent of meclofenoxate hydrochloride in sterile powder for injection by ${ }^{1} \mathrm{H}-\mathrm{NMR}$.

\begin{tabular}{|c|c|c|}
\hline Hydrogen proton & Chemical shift/ppm & Content/\% \\
\hline Internal standard & 6.319 & \\
\hline Sample-1 & 2.858 & 39.49 \\
\hline Sample-2 & 4.509 & 39.17 \\
\hline Sample-3 & 4.793 & 38.51 \\
\hline Sample-4 & 6.912 & 38.95 \\
\hline Sample-5 & 7.295 & 39.37 \\
\hline Average content $/ \%$ & \multicolumn{2}{|c|}{39.1} \\
\hline $\mathrm{RSD} / \%$ & \multicolumn{2}{|c|}{1.0} \\
\hline
\end{tabular}

Table 4. Compare the different method for the determination of meclofenoxate hydrochloride for injection.

\begin{tabular}{cccc}
\hline & Content & Sample hydrolysis in the determination & Sample pretreatment \\
\hline HPLC & $38.8 \%$ & Yes & Yes \\
DSC & $39.3 \%$ & No & No \\
${ }^{1}$ H-NMR & $39.1 \%$ & Yes & Yes \\
\hline
\end{tabular}


preparation and a rather quick and easy analysis. Therefore, the DSC and NMR method could be the complementation with the HPLC method for the assay of meclofenoxate content in meclofenoxate hydrochloride for injection.

\section{Acknowledgements}

The study was financed by the graduate research and innovation funding (14KY0412). We would like to thank Shanghai University of Engineering Science for financial support.

\section{References}

[1] El-Nashar, R.M., Abdel Ghani, N.T. and Hassan, S.M. (2012) Construction and Performance Characteristics of New Ion Selective Electrodes Based on Carbon Nanotubes for Determination of Meclofenoxate Hydrochloride. Analytica Chimica Acta, 730, 99-111. http://dx.doi.org/10.1016/j.aca.2011.10.069

[2] The State Pharmacopoeia Commission of PR China (2010) Meclofenoxate Hydrochloride. In: Pharmacopoeia of the People's Republic of China Edition, China Medical Science Press, Beijing, 663.

[3] El-Bardicy, M.G., Lotfy, H.M., El-Sayed, M.A. and El-Tarras, M.F. (2007) Stability Indicating Electrochemical Methods for the Determination of Meclophenoxate Hydrochloride and Pyritinol Dihydrochloride Using Ion-Selective Membrane Electrodes. Yakugaku Zasshi, 127, 201-208. http://dx.doi.org/10.1248/yakushi.127.201

[4] Fu, Z., Wang, L. and Wang, Y. (2009) Capillary Electrophoresis-Electrochemiluminescent Detection of N,N-Dimethyl Ethanolamine and Its Application in Impurity Profiling and Stability Investigation of Meclophenoxate. Analytica Chimica Acta, 638, 220-224. http://dx.doi.org/10.1016/j.aca.2009.02.024

[5] Hu, X.L., Xu, D.P., Liu, S.P., et al. (2010) Determination of Meclofenoxate Hydrochloride by Resonance Rayleigh Scattering Method Coupled with Flow Injection Technique. Analytical Letters, 43, 2125-2133. http://dx.doi.org/10.1080/00032711003698820

[6] Ni, B., Zhang, J.R., Zou, J.J., et al. (2010) A Simple and Sensitive HPLC Method for Quantification of the Metabolin of Meclofenoxate in Human Plasma. Journal of Chromatographic Science, 48, 353-357. http://dx.doi.org/10.1093/chromsci/48.5.353

[7] El-Bardicy, M.G., Lotfy, H.M., El-Sayed, M.A. and El-Tarras, M.F. (2007) Kinetic Study on the Degradation of Meclophenoxate Hydrochloride in Alkaline Aqueous Solutions by High Performance Liquid Chromatography. Yakugaku Zasshi, 127, 193-199. http://dx.doi.org/10.1248/yakushi.127.193

[8] Yang, H. and Thyrion, F.C. (1998) Determination of Six Pharmaceuticals and Their Degradation Products in ReversedPhase High Performance Liquid Chromatography by Using Amine Additives. Journal of Liquid Chromatography \& Related Technologies, 21, 1347-1357. http://dx.doi.org/10.1080/10826079808005882

[9] Malz, F. and Jancke, H. (2005) Validation of Quantitative NMR. Journal of Pharmaceutical and Biomedical Analysis, 38, 813-823. 